Baths and dressing room accommodation must be provided for both sexes. Just one other point before I conclude, the importance of providing a Laboratory to enable the Veterinary Inspector to carry out microscopical and bacteriological examination of material coming under his purview. No one can carry out the work of Meat Inspection without having recourse to the microscope.

\title{
The Spread and Control of Foot and Mouth Disease.
}

By D. A. E. САBOT, M.R.C.V.S., Veterinary Inspector, Ministry of Agriculture.

\section{(ABSTRACT.)}

OUTBREAKS of foot and mouth disease arising in this country no doubt usually originate from Continental sources ; though it is by no means clear how the virus is disseminated. During the period of demobilisation it is possible that in a few instances the virus was brought here by returning troops, but as the outbreaks became more numerous after demobilisation was practically completed and as unexplained outbreaks occurred from time to time before the war, this means of spread is of mere passing interest. Experience in this country lends very little support to the theory that infection is air-borne. The suggestion that birds might be responsible for introducing the disease can hardly be supported by available evidence. The processes to which the raw material is subjected in the manufacture of artificial feeding stuffs are probably destructive to the virus (if it should be present) either by exposure to heat or chemicals. The difficulty in indicating the probable means of introduction of virus appears to lie principally in the fact that it seems impossible to detect a common factor which can be considered to be a means of dissemination. In the local spread of disease infected animals play a principal part; and the spread of disease is facilitated by the movement of persons who may have visited infected premises, and by distribution of material, such as hay and straw, which may have been contaminated by affected animals.

The measures which aim at the prevention of introduction of the disease should continue in force, and the present practice of dealing with the disease by slaughter and prohibition of movement should not be abandoned in favour of isolation, as the hardships to the agricultural industry are much less under the present system than would be the case if prolonged isolation were adopted. The policy of slaughter has the further advantage of leaving no survivors, 


\section{Spread and Control of Foot and Mouth Disease.}

for among recovered animals there is a proportion which remain potential distributors of disease, at any rate intermittently, though to what extent and for how long is not definitely known; where every measure is adopted to curtail the spread of the disease, the importance of the carrier as a disseminator of infection must not be overlooked. Prompt reporting of suspected cases is essential to the rapid extinction of outbreaks. Disinfection of all contaminated material should receive early attention, and movement of contact animals should be inquired into without delay in order to prevent the establishment of secondary outbreaks, or at any rate, of reducing their number by isolation or slaughter of animals which have been exposed to infection. If, however, the disease became widespread, the policy of isolation would have to be adopted; but it is doubtful whether it would be wise to expose large numbers of animals to infection in order to shorten the duration of the outbreaks, as the virulence of the organism might thereby become intensified, with very serious effect among animals which are now nonresistant. At present there is no practicable means of immunising large numbers of animals against foot and mouth disease; though a safe method of producing active immunity without at the same time producing virus would be a useful adjunct to the policy now in force, and such a method would be of especial value if it became necessary to resort to isolation of affected animals instead of slaughter. 